\title{
Bir İldeki Hastanelerde Çalışan Hekimlerin İleri Teknoloji Kullanım Düzeyinin Belirlenmesi*
}

\section{Determination of Advanced Technology Usage Level of Physicians Working in Hospitals in a Province Gülay Yıldırımi, Şerife Karagözoğluii, Ezgi Yıldıziii, Sedat Özbayiv}

iProf.Dr.,Sivas Cumhuriyet Üniversitesi Tıp Fakültesi Temel Tıp Bölümü, Tıp Tarihi ve Etik AD.https://orcid.org/0000-0002-9589-7134

iiProf.Dr., Sivas Cumhuriyet Üniversitesi Sağlık Bilimleri Fakültesi Hemşirelik Esasları AD. https://orcid.org/0000-0002-9558-0786

iiiArş. Gör., Sivas Cumhuriyet Üniversitesi Suşehri Sağlık Yüksekokulu Hemşirelik Bölümü. https://orcid.org/0000-0002-7261-0129 ivUzm. Dr., Sivas Numune Hastanesi. https://orcid.org/0000-0002-8470-8529

öz

Amaç: Günümüzde insan hayatının her alanında hızlanan teknolojik değişimlerin etkisi sağlık sektörüne de yansımış durumdadır. Sürdürülebilir bir sağlık sisteminde hastalıkların önlenmesi, tanısı, tedavi süreci ve hastaların rehabilitasyonu için sağlık/tıbbi teknolojileri önem arz etmektedir. Bu araştırma, bir ildeki hastanelerde çalışan hekimlerin ileri teknoloji kullanım düzeyinin belirlenmesi amacıyla yapılmıştır.

Yöntem: Araştırma üniversite, devlet ve özel hastanede çalışan hekimler $(n=313)$ üzerinde yapılmıştır. Verilerin toplanmasında Kişisel Bilgi Formu ve Hekimlerin İleri Teknoloji Kullanım Görüşleri formu kullanılmıştır. Veriler frekans, ortalama, minimum ve maksimum değerler, standart sapma, Mann Whitney U testi, Kruskal-Wallis kullanılarak değerlendirilmiştir.

Bulgular: Hekimlerin yaş ortalaması 36.22 \pm 10.02 'dir. Katılımcıların $\% 57.5^{\prime}$ i erkek, \% 40.6'sı 1-5 ve 11 yıl ve üzerinde hizmet süresine sahiptir. Hekimlerin Illeri Teknoloji Kullanım Görüşleri toplam puan ortalaması 77.16 $\pm 12.62(34-102)$ olarak bulunmuştur. Cerrahi bölümlerde çalışan hekimlerin dahili bölümlerde çalışan hekimlere göre, kamu hastanesinde çalışan hekimlerin özel hastanede çalışan hekimlere göre, akademik ünvanı araştırma görevlisi olan hekimlerin, şu andaki kurumunda çalışma süresi 11 yıl ve üzeri olan hekimlerin ileri teknoloji kullanımına ve teknolojinin getireceği sorunların farkında olunduğuna ilişkin görüş puan ortalaması anlamlı düzeyde daha yüksek bulunmuştur.

Sonuç: Hekimlerin ileri teknoloji kullanımına yönelik olumlu görüşlerinin orta düzeyde olduğu belirlenmiştir. Bu sonuç doğrultusunda, teknolojiyi tedavide kullanmak ve değerlendirmek için uygun yöntemlerin belirlenmesinin önem arz etmesinin yanı sıra ileri teknolojinin yaygınlaşması ile koruyucu hekimlik uygulamalarının ikinci plana itilmesinin önlenmesi, tıp eğitiminin teknoloji bağımlı hekimler yetiştirecek biçimde yapılanmasının önüne geçilmesi büyük önem taşıyacağı düşünülmektedir.

Anahtar Kelimeler: Hekim, Illeri Teknoloji, Tıp

\section{ABSTRACT}

Aim: Today, the impact of technological changes accelerating in all areas of human life is also reflected in the health sector. In a sustainable health system, health/medical technologies are important for the prevention, diagnosis, treatment process and rehabilitation of patients. This research was conducted to determine the level of advanced technology use of physicians working in hospitals in a province.

Method: The research was conducted on physicians $(n=313)$ working in universities, public and private hospitals. Personal Information Form and Physicians' Advanced Technology Usage Opinions form were used to collect data. Data were evaluated using frequency, mean, minimum and maximum values, standard deviation, Mann Whitney $U$ test, Kruskal-Wallis.

Results: The mean age of the physicians was $36.22 \pm 10.02 .57 .5 \%$ of the participants are male, $40.6 \%$ have $1-5$ years of service and 11 years or more. Physicians' Advanced Technology Usage Views total score was found to be $77.16 \pm 12.62(34-102)$. Opinion score of physicians working in surgical departments compared to physicians working in internal departments, physicians working in public hospitals compared to physicians working in private hospitals, physicians with academic titles as research assistants, physicians with 11 years or more working time in their current institution, using advanced technology and being aware of the problems that technology will bring. was found to be significantly higher than the mean.

Conclusion: It was determined that the positive opinions of the physicians towards the use of advanced technology were moderate. In line with this result, it is thought that it is important to determine the appropriate methods to use and evaluate technology in treatment, as well as to prevent preventive medicine practices from being pushed into the background with the spread of advanced technology, and to prevent the structuring of medical education in a way that will train technology-dependent physicians.

Keywords: Physician, Advanced Technology, Medicine

\footnotetext{
*Mersin Üniversitesi Tıp Fakültesi Lokman Hekim Tıp Tarihi ve Folklorik Tıp Dergisi, 2022; 12 (1): $126-135$ DOI: $10.31020 /$ mutftd.1005680

e-ISSN: 1309-8004, ISSN 1309-761X

Geliş Tarihi - Received: 09 Ekim 2021; Kabul Tarihi - Accepted: 17 Kasım 2021

Iletişim - Correspondence Author: Ezgi Yıldız <ezgiyildiz58@hotmail.com>

Etik Kurul Onayı: Sivas Cumhuriyet Üniversitesi Girişimsel Olmayan Klinik Araştırmalar Etik Kurulu (Tarih: 11.09.2019,

Karar No: 2019-09/16)
} 


\section{Giriş}

Günümüzde insan hayatının her alanında hızlanan teknolojik değişimlerin etkisi sağlık sektörüne de yansımış durumdadır. Sürdürülebilir bir sağıık sisteminde hastalıkların önlenmesi, tanısı, tedavi süreci ve hastaların rehabilitasyonu için sağlık/tıbbi teknolojilerinin kullanımı önemlidir. ${ }^{1}$ Sağlık teknolojisi, bir hastalığı önlemek, teşhis ve tedavi etmek, rehabilitasyon veya uzun süreli bakım için kullanılan müdahale olarak tanımlanmaktadır. ${ }^{2}$

İleri tıbbi teknolojilerin kullanımı tanı ve tedavide katkı sağlarken etik, sosyal ve yasal sorunlara da yol açabilmektedir. ${ }^{3,4}$ Tıbbi teknoloji ile tedavi ve bakımın kalitesi artarken maliyeti düşüreceği, hastaya ilişkin bilgilerin kurumlar arasında paylaşımı sağlanarak hem hastanın farklı sağıık kurumlardan hizmet alması hem de hastaya ilişkin bilgilerin güvenilirliğini arttıracağı belirtilmektedir. Bununla birlikte internet ortamındaki sağık bilgilerinin güvenirliliği ve tele tıp sorumluluğu ayrı bir sorun olarak görülmekte olup, ileri teknoloji nedeniyle hastaların tıbbi bilgilerinin gizliliğinin korunması yetersiz kaldığı ve mahremiyeti tehdit ettiği belirtilmektedir. ${ }^{5,6}$

Yüksek teknoloji teşhis cihazlarına kolay erişim hekimlerin tıp etiğinin "faydalı olma" ilkesine bağlı kalmaları için önemli bir hedeftir. Ancak bu, "adalet" ilkesi çerçevesinde kararlar almayı da gerektirir. ${ }^{7}$ Kısıtlı kaynakların adil dağılımı, hekimlerin adalet çerçevesinde yükümlülüklerine göre etik değerlendirmeler yapmalarını zorunlu kılmaktadır. Adil dağıtım sorunlarına sahip olmak, bazılarının özel olarak diğerlerinden daha fazla kaynak elde etmesi anlamına gelmektedir. Oysaki sağlık hizmeti her birey için erişilebilir olmalıdır. ${ }^{8}$ Sağlık teknolojisinden daha fazla yararlanmak daha iyi hasta sonuçlarını ve sağlığı garanti etmeyebilir. ${ }^{9}$ illeri teknoloji kullanımına yönelik yapılan reklamlar yanlış bilgilendirme ve yönlendirme yapabilmekte ve hastaların zarar görmesine, özerkliklerinin yok sayılmasına ve adalet ilkesinin zedelenmesine de neden olabilmektedir.

Sağlık hizmetlerinde kullanılan teknik ve teknolojilerde görülen çok hızlı gelişme ve değişimler hasta, hasta yakınları ve bu cihazları kullanan hekimlerin davranış biçimlerini de etkilemektedir. ${ }^{10}$ Tıbbi teknolojinin gelişmesine rağmen tedavi sürecinde hekim-hasta ilişkisi hala önemli bir faktör olmaya devam etmektedir. Hasta çokluğu nedeniyle hekimin hastasına yeteri kadar zaman ayıramaması ve özeni gösterememesi klasik tıbbın muayene yöntemleri yerine yüksek teknolojinin kullanımını ön plana çıkarabilmektedir. Bu bağlamda hastanın hekime duyduğu güvende ve aralarındaki iletişimde yaşanan olumsuz durumlar tedavinin gereklerini yerine getirme açısından sorunlara yol açabilmektedir. ${ }^{11,12}$ Buna ek olarak ileri teknoloji kullanımı hakkında hekimlerin yeterli bilgi ve deneyime sahip olmaması hekim hatalarını da arttırabilmektedir. Tıbbi malpraktis sayısında Türkiye' de ve dünyada son yıllarda önemli bir artış söz konusudur. ${ }^{13}$ Bu artışın en önemli sebepleri olarak sağlıktaki teknolojinin gelişmesi ile hasta ve hasta yakınlarının beklentilerinin artması medyanın olumsuz tutumu olduğu bildirilmektedir. ${ }^{14}$ Tıbbi bilimsel bilgi ve teknoloji üretimindeki artış ve mesleki uygulamanın sürekli kendini yenilemesi karşısında, hekimin bilgi ve teknolojilerinin kullanım uygunluğunu değerlendirebilmesi, etkili ve etik kullanımı konusunda da yetkinlik göstermesi beklenmektedir. ${ }^{15} \mathrm{Bu}$ bağlamda, bir ildeki hastanelerde çalışan hekimlerin ileri teknoloji kullanım düzeyinin belirlenmesi amacıyla yapılmıştır.

\section{Yöntem}

\section{Araştırmanın Tipi}

Araştırmanın tipi tanımlayıcıdır. 


\section{Araştırmanın Evren ve Örneklemi}

Araştırmanın evrenini Eylül 2019-Haziran 2020 tarihleri arasında Sivas ili Merkez'de bulunan üniversite, devlet ve özel hastanede çalışan öğretim üyesi, uzman hekim ve araştırma görevlisi hekimler ( $n=661)$ oluşturmuştur. Araştırma örneklemini ise kurumlarında en az bir yıl çalışmış olan, veri toplama araçlarını eksizsiz dolduran ve çalışmayı katılmayı kabul eden hekimler $(n=313)$ oluşturmuştur.

Bağımlı Değişken: Illeri teknoloji kullanım düzeyi

Bağımsız Değişen: Yaş, cinsiyet, akademik unvan, çalıştığı birim ve kurum, hizmet süresi

\section{Veri Toplama Araçları}

Araştırma verilerinin toplanmasında Kişisel Bilgi Formu ve Hekimlerin İleri Teknoloji Kullanım Görüşleri (HiTKG) olmak üzere toplam iki form kullanılmıştır.

\section{Kişisel Bilgi Formu}

Araştırmacılar tarafından hazırlanan bu formda hekimlerin yaşını, cinsiyetini, akademik unvanını, çalıştığı birimi, çalıştı̆̆ı kurumu, şu anki kurumunda çalışma yılını, toplam hizmet yılını ve çalıştı̆̆ı birimdeki teknoloji kullanım düzeyi puan ortalamasını belirlemeye yönelik toplamda sekiz soru bulunmaktadır. Çalıştığı birimdeki teknoloji kullanım düzeyi puan ortalamasını belirlemek amacıyla hekimlerden 1-10 arasında (en az:1; en çok:10) puan vermeleri istenmiştir.

\section{Hekimlerin ileri Teknoloji Kullanım Görüşleri (HITKG)}

Araştırmacılar tarafından hekimlerin ileri teknoloji kullanım düzeyini belirlemek amacıyla oluşturulan bu formda üçlü likert tipte (Katılıyorum, Kararsızım, Katılmıyorum) toplam 34 soru bulunmaktadır. Formun puanlanması "Katılıyorum:3; Kararsızım:2; Katılmıyorum:1" olarak değerlendirilmiştir. Bu soru formundan alınacak en düşük puan 34, en yüksek puan ise 102 olup, alınan puanın yüksek olması ileri teknoloji kullanımına ve teknolojinin getireceği sorunların farkında olunduğuna ilişkin görüşleri göstermektedir.

\section{Verilerin Değerlendirilmesi}

Araştırmadan elde edilen veriler istatistiksel olarak analiz edilmiştir. Araştırma verilerin değerlendirilmesinde sayı-yüzdelik dağılımı, standart sapma, ortalama, minimum ve maximum kullanılmıştır. Verilerin normalliğinin değerlendirilmesinde Kolmogorov Smirnov testi kullanılmıştır. Normal dağılım göstermeyen bağımsız iki grubun puan ortalamaları karşılaştırııırken Mann Whitney-U testi, bağımsız ikiden fazla gruba ait ölçek puan ortalamaları karşılaştırıırken Kruskal Wallis analizi kullanılmıştır. Elde edilen bulgular \%95 güven aralığında $p<0.05$ anlamlılık düzeyinde değerlendirilmiştir.

\section{Araştırmanın Sınırlılıkları}

Araştırmanın veri toplama sürecinin bir kısmının Covid-19 sürecine denk gelmesi ve araştırmanın örneklemini sadece bir ildeki hastanelerde çalışan hekimlerin oluşturması genellenebilirlik açısından araştırmanın sınırıııklarını oluşturmaktadır.

\section{Etik Onay}

Araştırma yapılmadan önce Sivas Cumhuriyet Üniversitesi Girişimsel Olmayan Klinik Araştırmalar Etik Kurulu'na başvurularak Etik Kurul Onayı (Karar No: 2019-09/16; Tarih: 11.09.2019) ve araştırmanın yapılacağı kurumlardan yazılı izin alınmıştır. 


\section{Bulgular}

Hekimlerin yaş ortalaması 36.22 \pm 10.02 olup, \%57.5'i erkek, \%51.1'i araştırma görevlisi, \%51.1'inin alanı cerrahi birimler, \%87.2'sinin çalıştığı kurum kamu hastanesi, \%73.2'sinin şuandaki kurumunda çalışma yılı 15 yıl, \%40.6'sının toplam hizmet süresi 1-5 yıl ve 11 yıl üzeri olarak belirlenmiştir. Hekimlerin çalıştığı kliniklerde teknoloji kullanım düzeyi puan ortalamasının ise $5.74 \pm 2.14$ olduğu saptanmıştır (Tablo 1).

Tablo 1. Hekimlerin Demografik Özellikler Tablosu ( $N=313$ )

\begin{tabular}{|c|c|}
\hline Demografik Özellikler & \\
\hline \multicolumn{2}{|l|}{ Yaş (X士SS) } \\
\hline Öğretim Üyesi & $47.06 \pm 8.43$ \\
\hline Uzman Hekim & $41.84 \pm 8.03$ \\
\hline Araştırma Görevlisi & $28.89 \pm 3.97$ \\
\hline \multirow[t]{2}{*}{ Genel yaş ortalaması } & $\mathbf{X} \pm \mathrm{SS}=36.22 \pm 10.02 \quad$ Min-Max $=24-67$ \\
\hline & $\mathrm{n}(\%)$ \\
\hline \multicolumn{2}{|l|}{ Cinsiyet } \\
\hline Kadın & $133(42.5)$ \\
\hline Erkek & $180(57.5)$ \\
\hline \multicolumn{2}{|l|}{ Akademik unvanı } \\
\hline Öğretim Üyesi & $60(19.2)$ \\
\hline Uzman Hekim & $93(29.7)$ \\
\hline Araştırma Görevlisi & $160(51.1)$ \\
\hline \multicolumn{2}{|l|}{ Çalıştığı Birim } \\
\hline Dahili birimler & $153(48.9)$ \\
\hline Cerrahi birimler & $160(51.1)$ \\
\hline \multicolumn{2}{|l|}{ Çalıştığı kurum } \\
\hline Kamu hastanesi & $273(87.2)$ \\
\hline Özel hastanesi & $40(12.8)$ \\
\hline \multicolumn{2}{|l|}{ Şuandaki kurumdaki çalışma süresi } \\
\hline $1-5$ yıl & $229(73.2)$ \\
\hline $6-10 \mathrm{yıl}$ & $42(13.4)$ \\
\hline 11 yıl ve üzeri & $42(13.4)$ \\
\hline \multicolumn{2}{|l|}{ Toplam hizmet süresi } \\
\hline $1-5$ yıl & $127(40.6)$ \\
\hline $6-10$ yıl & $59(18.8)$ \\
\hline 11 yıl ve üzeri & $127(40.6)$ \\
\hline \multicolumn{2}{|l|}{ Çalıştığı birimdeki teknoloji kullanım düzeyi puan } \\
\hline ortalaması (X士SS) & $5.74 \pm 2.14$ \\
\hline
\end{tabular}

Tablo 2' de hekimlerin bazı özelliklerine göre ITKG puan ortalamalarının dağıımı yer almaktadır. Hekimlerin ITKG toplam puan ortalaması 77.16 \pm 12.62 olarak bulunmuştur. Akademik unvanı araştırma görevlisi olan hekimlerin diğer akademik unvana sahip hekimlere göre, cerrahi bölümlerde çalışan hekimlerin dahili bölümlerde çalışan hekimlere göre, kamu hastanesinde çalışan hekimlerin özel hastanede çalışan hekimlere göre, şu andaki kurumunda çalışma süresi 11 yıl ve üzeri olan hekimlerin diğer hekimlere göre íTKG puan ortalamasının istatistiksel olarak anlamlı düzeyde daha yüksek olduğu belirlenmiştir $(p<0.05)$.

Tablo 2. Hekimlerin Bazı Özelliklerine Göre ITKG Puan Ortalamalarının Dağılımı Tablosu

\begin{tabular}{|c|c|}
\hline & ITKG Toplam Puan \\
\hline $\mathrm{X} \pm \mathrm{SS}$ & $77.16 \pm 12.62$ \\
\hline \multirow[t]{2}{*}{ M(Min-Max) } & 78(35-99) \\
\hline & M(Min-Max) \\
\hline \multicolumn{2}{|l|}{ Cinsiyet } \\
\hline Kadın $(n=133)$ & $77(35-99)$ \\
\hline \multirow[t]{2}{*}{ Erkek $(n=180)$} & $78(40-90)$ \\
\hline & $Z=-0.372, p=0.710$ \\
\hline \multicolumn{2}{|l|}{ Akademik unvanı } \\
\hline Öğretim Üyesi ( $n=60)$ & $76.5(40-99)$ \\
\hline Uzman Hekim ( $n=93)$ & $76(35-99)$ \\
\hline \multirow[t]{2}{*}{ Araştırma Görevlisi ( $n=160)$} & $80(39-99)$ \\
\hline & $K W=6.888, p=0.032 *$ \\
\hline
\end{tabular}




\begin{tabular}{lc}
\hline Çalıştığı Birim & $76(41-99)$ \\
Dahili birimler ( $n=153)$ & $80(35-99)$ \\
Cerrahi birimler ( $n=60)$ & $Z=-2.491, p=0.013^{*}$ \\
& \\
Çalıştığı kurum & $79(35-99)$ \\
Kamu hastanesi ( $n=273)$ & $73(43-99)$ \\
Özel hastanesi ( $n=40)$ & $Z=-2.328, p=0.020^{*}$ \\
& \\
Şuandaki kurumda çalışma süresi & $78(39-99)$ \\
1-5 yıl ( $n=229)$ & $75(35-99)$ \\
$6-10$ yıl ( $n=42)$ & $81.5(41-99)$ \\
11 yıl ve üzeri ( $n=42)$ & $K W=6.246, p=0.044^{*}$ \\
& \\
Toplam hizmet süresi & $79(39-99)$ \\
$1-5$ yıl ( $n=127)$ & $78(51-99)$ \\
$6-10$ yıl ( $n=59)$ & $77(35-99)$ \\
11 yıl ve üzeri ( $n=127)$ & $K W=\mathbf{2 . 8 0 7 , p = 0 . 2 4 6}$ \\
\end{tabular}

M(Min-Max): Medyan(Minimum-Maximum); iTKG: Ileri Teknoloji Kullanım Görüşleri ${ }^{*} p<0.05$

Tablo 3'e göre, hekimlerin ileri teknoloji kullanım görüşleri incelendiğinde en yüksek yüzdeye sahip ifadelerin "ileri teknoloji araç ve yöntemlerini kullanan hekim bu konuda yeterli bilgi-beceriye sahip değilse ciddi hataların ortaya çıkmasına neden olur", "Yüksek teknolojiye olan güven ve yoğun propaganda sonucu hastalar gerekmese bile doktorlarına bu incelemelerin yapılması için baskı yapmaktadır" "Hasta çokluğu nedeniyle hekimin hastasına yeteri kadar zaman ayıramaması ve özeni gösterememesi klasik tıbbın muayene yöntemleri yerine yüksek teknolojinin kullanımını ön plana çıkarmaktadır" ve "Teknolojinin denetimsiz ve plansız alınması yararııı̆ı kısıtlanmakta ve sınırlı kaynakların kullanılmasını olumsuz etkilemektedir” olduğu görülmektedir.

En düşük yüzdeye sahip ifadelerin ise "Yardımcı üreme teknikleri hayatın ve ölümün nerede başlayıp bittiği konusunda sorunlara neden olmaktadır", "ileri teknoloji gerektiren uygulamanın yapılmasına karar veren hekimle bu işlemi yapacak olan hekimin aynı olması kötüye kullanım riskini artırmaktadır" ve "Genetik gelişmeler bireylerin genetik özellikleri nedeniyle işlerini kaybetmesi ve damgalanmasına yol açmaktadır" olduğu belirlenmiştir.

Tablo 3. Hekimlerin İleri Teknoloji Kullanım Görüşleri Dağılım Tablosu

\begin{tabular}{|c|c|c|c|}
\hline & $\begin{array}{c}\text { Katıliyorum } \\
\mathrm{n}(\%)\end{array}$ & $\begin{array}{c}\text { Kararsızım } \\
\mathrm{n}(\%)\end{array}$ & $\begin{array}{c}\text { Katılmıyorum } \\
\mathrm{n}(\%)\end{array}$ \\
\hline $\begin{array}{l}\text { 1.illeri teknoloji araç ve yöntemlerini kullanan hekim bu konuda yeterli bilgi- } \\
\text { beceriye sahip değilse ciddi hataların ortaya çıkmasına neden olur. }\end{array}$ & $270(86.3)$ & $18(5.8)$ & $25(8.0)$ \\
\hline $\begin{array}{l}\text { 2. Yüksek teknolojiye olan güven ve yoğun propaganda sonucu hastalar } \\
\text { gerekmese bile doktorlarına bu incelemelerin yapılması için baskı yapmaktadır. }\end{array}$ & $268(85.6)$ & $21(6.7)$ & $24(7.7)$ \\
\hline $\begin{array}{l}\text { 3. Hasta çokluğu nedeniyle hekimin hastasına yeteri kadar zaman ayıramaması } \\
\text { ve özeni gösterememesi klasik tıbbın muayene yöntemleri yerine yüksek } \\
\text { teknolojinin kullanımını ön plana çıkarmaktadır. }\end{array}$ & $247(78.9)$ & $19(6.1)$ & $47(15.0)$ \\
\hline $\begin{array}{l}\text { 4.Teknolojinin denetimsiz ve plansız alınması yararlılığı kısıtlanmakta ve sınırlı } \\
\text { kaynakların kullanılmasını olumsuz etkilemektedir. }\end{array}$ & $240(76.7)$ & $39(12.5)$ & $34(10.9)$ \\
\hline $\begin{array}{l}\text { 5. Endikasyonsuz kullanılan ileri teknoloji nedeniyle sağlığa ayrılan pay heba } \\
\text { edilmektedir. }\end{array}$ & $238(76.0)$ & 29(9.3) & $46(14.7)$ \\
\hline $\begin{array}{l}\text { 6. Gereksinim olduğunda hekimlik uygulamalarında ileri teknoloji sistemlerine } \\
\text { Türkiye'nin her tarafından herkesin her zaman ulaşabilmesi mümkün değildir. }\end{array}$ & $233(74.4)$ & $35(11.2)$ & $45(14.4)$ \\
\hline $\begin{array}{l}\text { 7. Genetik gelişmeler gıdaların doğal özelliklerinin kaybolmasına ve insan } \\
\text { sağlığını risk etmesine yol açmaktadır. }\end{array}$ & $232(74.1)$ & $37(11.8)$ & $44(14.1)$ \\
\hline $\begin{array}{l}\text { 8. Ülkemizde ileri teknoloji kullanımı büyük ölçüde gelişmiş ülkelere bağımlı } \\
\text { olup, bu ülkelerin pazarını oluşturmaktadır }\end{array}$ & $227(72.5)$ & $41(13.1)$ & $45(14.4)$ \\
\hline $\begin{array}{l}\text { 9. İkinci el cihazların çokluğu, yeni cihaz teminindeki plansızlık ve denetimsizlik } \\
\text { yeterli servis ve bakım hizmetlerinin elde edilememesi ülkemizde cihaz } \\
\text { çöplüğünün oluşmasına yol açmıştır. }\end{array}$ & $224(71.6)$ & $47(15.0)$ & $42(13.4)$ \\
\hline
\end{tabular}




\begin{tabular}{|c|c|c|c|}
\hline $\begin{array}{l}\text { 10. Günümüzde tele-tıp uygulamalarında ve internet ortamındaki sağlık } \\
\text { bilgilerinin güvenirliliği önemli bir sorundur. }\end{array}$ & $222(70.9)$ & $44(14.1)$ & $47(15.0)$ \\
\hline $\begin{array}{l}\text { 11. Sağlık sektörünün her kademesinde yüksek teknolojili teşhis- tedavi } \\
\text { yöntemlerinin çok gerekli olduğu yönünde hastalar yanlış bilgilendirilmektedir. }\end{array}$ & $208(66.5)$ & $42(13.4)$ & $63(20.1)$ \\
\hline $\begin{array}{l}\text { 12. İyi yetişmeyen hekimler klasik muayene yöntemleriyle tanı koymada } \\
\text { kendilerine olan güvensizlikleri ve korkuları nedeniyle ileri teknoloji } \\
\text { yöntemlerine gereksiz başvurabilmektedir. }\end{array}$ & $201(64.2)$ & $44(14.1)$ & $68(21.7)$ \\
\hline $\begin{array}{l}\text { 13. İleri teknoloji kullanımına yönelik yapılan reklamlar yanlış bilgilendirme ve } \\
\text { yönlendirme yapabilmekte ve hastaların zarar görmesine, özerkliklerinin yok } \\
\text { sayılmasına ve adalet ilkesinin zedelenmesine neden olmaktadır. }\end{array}$ & 198(63.3) & $53(16.9)$ & $62(19.8)$ \\
\hline $\begin{array}{l}\text { 14. Genetik açıdan sorunları saptanan bireyin sigorta kapsamı dışında } \\
\text { bırakııması nedeniyle sağılı hizmetlerine ulaşması son derece zorlaşacaktır. }\end{array}$ & $190(60.7)$ & $74(23.6)$ & 49(15.7) \\
\hline $\begin{array}{l}\text { 15. İleri teknoloji kullanımı büyük katkılar sağlarken bir yandan da etik, sosyal } \\
\text { ve yasal sorunlara yol açmaktadır. }\end{array}$ & 187(59.7) & $40(12.8)$ & $86(27.5)$ \\
\hline $\begin{array}{l}\text { 16. Yeni teknolojik yöntemler henüz standartlaşmamış yöntemlerdir. } \\
\text { Standartlaşmamış bir uygulamanın yapılmasıyla ortaya çıkabilecek } \\
\text { olumsuzluklar da malpraktis olarak hekimin karşısına çıkmaktadır. }\end{array}$ & $183(58.5)$ & $62(19.8)$ & $68(21.7)$ \\
\hline $\begin{array}{l}\text { 17. Ileri teknoloji ile birlikte hekimin ilgi alanı hasta olması gerekirken hastalık } \\
\text { olmaya başlamıştır. }\end{array}$ & $182(58.1)$ & $48(15.3)$ & $83(26.5)$ \\
\hline $\begin{array}{l}\text { 18. Daha çok satış daha çok kar kuralı nedeniyle hekimler ve sağlık yöneticileri } \\
\text { üretici-satıcı firmaların yoğun propagandası altındadır. }\end{array}$ & $181(57.8)$ & $57(18.2)$ & $75(24.0)$ \\
\hline $\begin{array}{l}\text { 19. Tıbbi teknolojideki hızlı gelişmeler yapılan kötü uygulamaların malpraktis ya } \\
\text { da komplikasyon olup olmadığı konusundaki yorumları etkileyecektir. }\end{array}$ & $180(57.5)$ & $77(24.6)$ & $56(17.9)$ \\
\hline $\begin{array}{l}\text { 20. Çeşitliliğin kaybolacağı, tıbbi gerekçelerle değil kişisel gerekçelerle yapılma } \\
\text { olasılığı, ortaya çıkacak canlıların özürlü olma olasılığı gibi nedenlerle klonlama } \\
\text { yapıımamalıdır. }\end{array}$ & $180(57.5)$ & $87(27.8)$ & $46(14.7)$ \\
\hline $\begin{array}{l}\text { 21. Hekim endüstri ilişkisi ve teknolojiye bağımlı tedavi edici hizmetlerin öncelik } \\
\text { kazanması sağlığın kar getirecek bir ticari alan olarak kabul edilmesine yol } \\
\text { açmaktadır. }\end{array}$ & $156(49.8)$ & $66(21.1)$ & $91(29.1)$ \\
\hline $\begin{array}{l}\text { 22. İleri teknolojinin kullanımı sağlık hizmetlerinin daha pahalı hale gelmesine } \\
\text { yol açmaktadır. }\end{array}$ & $154(49.2)$ & $47(15.0)$ & $112(35.8)$ \\
\hline $\begin{array}{l}\text { 23. Günümüzde teknoloji kullanımı hekimin kişisel bilgi ve becerisinin yerine } \\
\text { geçmiş, mekanik araçların gelişmişliğini-yaygınlığını artırmıştır. }\end{array}$ & $150(47.9)$ & $42(13.4)$ & $121(38.7)$ \\
\hline 24. Çıkar sağlamak için gereksiz teknoloji kullanımı sıklıkla yapılmaktadır. & 149(47.6) & $60(19.2)$ & $104(33.2)$ \\
\hline $\begin{array}{l}\text { 25. Yeni gelişen tedavi ve teknikler nafile tedavi tartışmalarını gündeme } \\
\text { getirmektedir }\end{array}$ & $149(47.6)$ & $81(25.9)$ & $83(26.5)$ \\
\hline $\begin{array}{l}\text { 26. İleri teknolojik uygulamaların tıbbın standart olarak kabul edilebileceği bir } \\
\text { uygulama haline gelmesi için geçen zaman önemli bir dezavantajdır. }\end{array}$ & $147(47.0)$ & $79(25.2)$ & $87(27.8)$ \\
\hline $\begin{array}{l}\text { 27. Ileri teknoloji kullanma eğilimi koruyucu sağlık hizmetlerine olan ilgiyi } \\
\text { azaltmaktadır. }\end{array}$ & 138(44.1) & $132(42.2)$ & $43(13.7)$ \\
\hline $\begin{array}{l}\text { 28. Yardımcı üreme teknikleri embriyonun ticari bir materyal haline dönüşmesi } \\
\text { sorunlara neden olmaktadır. }\end{array}$ & $133(42.5)$ & $63(20.1)$ & $117(37.4)$ \\
\hline 29. Genetik gelişmeler toplumda cinsiyet tercihi sorunlarına yol açmaktadır. & $133(42.5)$ & $69(22.0)$ & $111(35.5)$ \\
\hline $\begin{array}{l}\text { 30. İleri teknoloji nedeniyle hastaların tıbbi bilgilerinin gizliliğinin korunması } \\
\text { yetersiz kalmakta ve mahremiyeti tehdit etmektedir. }\end{array}$ & $121(38.7)$ & $56(17.9)$ & $136(43.5)$ \\
\hline $\begin{array}{l}\text { 31. Yardımcı üreme teknikleri annelik ve babalık kavramlarının değişmesine ve } \\
\text { yasal problemlere neden olmaktadır. }\end{array}$ & $119(38.0)$ & $51(16.3)$ & $143(45.7)$ \\
\hline $\begin{array}{l}\text { 32. Genetik gelişmeler bireylerin genetik özellikleri nedeniyle işlerini } \\
\text { kaybetmesi ve damgalanmasına yol açmaktadır. }\end{array}$ & $117(37.4)$ & $80(25.6)$ & $116(37.1)$ \\
\hline $\begin{array}{l}\text { 33. İleri teknoloji gerektiren uygulamanın yapılmasına karar veren hekimle bu } \\
\text { işlemi yapacak olan hekimin aynı olması kötüye kullanım riskini artırmaktadır. }\end{array}$ & $114(36.4)$ & $65(20.8)$ & $134(42.8)$ \\
\hline $\begin{array}{l}\text { 34. Yardımcı üreme teknikleri hayatın ve ölümün nerede başlayıp bittiği } \\
\text { konusunda sorunlara neden olmaktadır. }\end{array}$ & $92(29.4)$ & $68(21.7)$ & $153(48.9)$ \\
\hline
\end{tabular}

\section{Tartışma}

Araştırmamızda akademik unvanı araştırma görevlisi olan hekimlerin diğer akademik unvana sahip hekimlere göre ileri teknoloji kullanımına ve teknolojinin getireceği sorunların farkında olunduğuna ilişkin görüş puan ortalamasının anlamlı düzeyde yüksek olduğu görülmüştür. Bu durum tıp fakültesi öğretim üyelerinin yaşça daha büyük olmaları, gelenekselleştirilmiş bir eğitim-öğretim veya tanı ve tedavinin sürdürülüyor olması, zaman sıkıntısı yaşamaları, teknoloji donanım imkanlarını etkin kullanamamaları ya da verilen eğitimlerin teknoloji ile entegre edilememesi ile açıklanabilir. Araştırma görevlisi olan doktorların ise genç, teknolojiye 
ilgi duymaları, çalışma deneyimlerinin az olması dolayısıyla malpraktise konu olan durumla karşılaşma noktasında kendilerini endişeli hissetmeleri ve buna ilişkin bir hukuki durumun içinde bulunmak istememelerinin bir sonucu olarak veya özellikle üniversite hastanelerinde araştırma görevlileri tanı ve tedavi teknolojilerini kullanırken hocalarının direktifleri doğrultusunda daha fazla tıbbi teknoloji kullanımına yönelebilecekleri düşünülmektedir. Ayrıca teknoloji kullanımına eğilimi olan asistanların uzmanlık konusunda daha istekli oldukları ve birinci basamak sağlık hizmetlerini önemsiz buldukları görülmektedir. Çalışmamız bulgularını destekler nitelikte, tıp fakültesi öğretim üyeleri ile yapılan bir çalışmada yaşın artması ile birlikte hekimlerin teknolojik gelişmeleri takip edememe ve yeterli düzeyde kullanamama endişesi yaşadıkları sonucu bulunmuştur. ${ }^{16}$ Zayim ve Saka çalışmasında eğitimde öğretim üyeleri tarafından teknoloji kullanımının değerli algılandığını ancak, öğretim teknolojilerini çok fazla benimsemediklerini belirtmiştir. ${ }^{17}$

Çalışmamızda cerrahi bölümlerde çalışan hekimlerin dahili bölümlerde çalışan hekimlere göre ileri teknoloji kullanımına ve teknolojinin getireceği sorunların farkında olunduğuna ilişkin görüş puan ortalaması anlamlı düzeyde daha yüksek bulunmuştur. Bu durum üroloji, ortopedi ve travmatoloji, genel cerrahi, kadın hastalıkları ve doğum gibi bölümlerde tanı ve tedavi amaçlı daha çok teknolojiye gereksinim duyulması ile açıklanabilir. Ayrıca kamu hastanesinde çalışan hekimlerin özel hastanede çalışan hekimlere göre, ileri teknoloji kullanımına ve teknolojinin getireceği sorunların farkında olunduğuna ilişkin görüş puan ortalamasının istatistiksel olarak anlamlı düzeyde daha yüksek olduğu belirlenmiştir. Bu durum, üniversite ve devlet hastanelerinin yatak kapasitelerinin yüksek olması, spesifik ve karmaşık tıbbi işlemler yapmaları nedeni ile tıbbi teknolojiye daha fazla intiyaç duyan sağlık kuruluşları olmaları ile açıklanabilir. Bununla birlikte kamu hastanelerinde çalışan hekimlerin ileri teknoloji kullanım oranlarının yüksek olması; özel hastanelerde tanısal tetkiklerin çok pahalı olması nedeni ile hastaların tetkiklerini kamu hastanelerinde yaptırması da bir faktör olarak düşünülmektedir. Bu yönden hekimlerin ve akademisyenlerin teşhis ve tedavi sırasında hayata geçirdikleri yeni uygulamaların ve buluşların tıbbi cihaz teknolojilerine yön vermede son derece önemli olacağına inanılmaktadır.

Yapılan bu araştırmada, şu andaki kurumunda çalışma süresi 11 yıl ve üzeri olan hekimlerin ileri teknoloji kullanımına ve teknolojinin getireceği sorunların farkında olunduğuna ilişkin görüş puan ortalamasının istatistiksel olarak anlamlı düzeyde daha yüksek olduğu belirlenmiştir. Hekimler kullandıkları mevcut teknolojilerin farklı kullanım alanlarına ilişkin yeni fikirlerin kaynağı olarak düşünüldüğünde bu sonuç, kurumunda uzun süre çalışan hekimlerin kurumlarındaki hali hazırda var olan ve yeni ürünler ile ilgili ihtiyaçları belirleyebilmeleri, kurumlarında bulunan teknolojik aletlerin kullanılabilme imkanlarıla ve mesleki deneyimlerinin getirmiş olduğu bir durumla açıklanabilir.

Kullanım ve maliyet açısından tıbbi teknolojinin ve özellikle hastanelerde tıbbi görüntüleme teknolojisinin önemi gün geçtikçe daha da artmaktadır. Çıkar sağlamak için gereksiz teknoloji kullanımı tıbbi etik sorun oluşturmaktadır. Çalışmamızda hekimlerin tıbbi teknoloji kullanım görüşleri ifadesinde "Teknolojinin denetimsiz ve plansız alınması yararlılığı kısıtlanmakta ve sınırlı kaynakların kullanılmasını olumsuz etkilemektedir." ifadesinin yüksek ortalamaya sahip bir ifade olduğu belirlenmiştir. Bu ifade ile araştırmamız kapsamındaki hekimlerin pahalı ve gereksiz tıbbi tanı ve tedavi için kullanılan testlerin sağlık bakım hizmetleri üzerindeki olumsuz etkisinin farkında olduklarını söyleyebiliriz. Yapılan çalışmalar araştırma bulgumuzu destekler niteliktedir. Robotik Cerrahi (RC) ile ilgili yapılan çalışmalarda RC sisteminin olumlu yönlerinin laparoskopik cerrahinin sunduğu olanaklardan daha fazla olmadığı veya sağladığı yararlara nazaran sistemin çok maliyetli olduğu ileri sürülmüştür. ${ }^{18}$ Bu bağlamda, en uygun zamanda sağlanan uygun tıbbi teknolojiyle yapılan muayene ile gereksiz maliyetler düşürülebilir, hastaneye yatışları kısaltılabilir ve maliyetleri artıran işlemlere olan ihtiyaç azaltılabilir. Sağlık çalışanları adaletli bir sağlık hizmetinin sağlanması ve sağlık için ayrılan kaynakların uygun kullanılması için çalışmalıdır. Aşırı kullanımının önüne geçmek için sağıı 
politikalarının geliştirilmesi, sağlık hizmet önceliklerinin belirlenmesi, sınırlı teknolojik imkanların adil paylaşımı, hekim davranışları, hasta beklentileri, eğitim ve maddi teşvikler üzerinde durulması gerektiği düşünülmektedir.

Araştırmamızda hekimlerin ileri teknoloji kullanım görüşlerinde bir diğer yüksek ifade ortalaması "Yüksek teknolojiye olan güven ve yoğun propaganda sonucu hastalar gerekmese bile doktorlarına bu incelemelerin yapılması için baskı yapmaktadır." olarak belirlenmiştir. Bu durum birçok hastanın; arkadaş, aile, medya veya tıbbi görüntüleme hizmet kullanıcılarının etkisi altında kalarak teknolojik hizmete ihtiyaç duymaları ile açıklanabilir. Kamu veya özel hastane olsun herhangi bir sağlık kurumunun, yüksek teknolojili mevcut bir tıbbi cihazının bir üst modeline sahip olması hasta tercihlerini önemli ölçüde değiştirebilmektedir. Daha fazla hasta çekmek ve hastaları özel sağlık kuruluşlarına yönlendirmek için tıptaki gelişmelerin halka abartı biçimde yansıtılması etik bir sorun teşkil etmektedir. Yapılan çalışmalarla başta Bilgisayarlı Tomografi (BT) görüntüleme olmak üzere nükleer tıbba maruz kalmanın gelecek yıllarda kanserlerin \%2'sinin ana sebebi olacağı ön görülmektedir. ${ }^{19}$ Bu durumda gerek hekimlerde gerekse hastalarda tıbbi görüntüleme ile ilişkili radyasyona maruz kalma konusunda radyasyon bilincinin oluşturulmasının büyük önem arz edeceği düşünülmektedir.

Teknolojik gelişmelerle birlikte, sağlık alanında kullanılan teknik araç ve gereçler gelişmiş ve bunun sonucunda sorumluluk alanı genişlemiştir. İleri teknolojinin yanlış yönlendirmesi ya da hatalı şekilde uygulanması hasta bireyin maddi veya manevi olarak zarar görmesine yol açabilmektedir. Çalışmamızda hekimlerin ileri teknoloji kullanım görüşlerinde ortalaması yüksek bir diğer ifadenin "ileri teknoloji araç ve yöntemlerini kullanan hekim bu konuda yeterli bilgi-beceriye sahip değilse ciddi hataların ortaya çıkmasına neden olur." olduğu saptanmıştır. Bu durum teknolojik aletlerin çalışmadığı veya kusurlu çalıştığı, müdahale sırasında hata vermesi ya da hekimin teknolojik yöntemleri etkili bir şekilde kullanamaması ile açıklanabilir. Ayrıca gelişmiş teknolojinin, hekimlik pratiğini tıbbi bilgiden daha çok etkilediğini ve temel kriteri, teşhiste kullanılan mekanik araçların gelişmişliği oluşturduğu düşünülmektedir. Tıp uygulaması, çalışma alanının insan vücudu olduğu ve insan üzerindeki her tip uygulamayı kapsadığı için farkıı bir yaklaşımı ve titizliği gerektirmektedir. Literatür çalışmaları bulgularımızı destekler niteliktedir. Usluoğulları ve arkadaşları çalışmasında hastanın robotdestekli safra kesesi ameliyatı sırasında bağırsak delinmesi sonucu zarar görmesi üzerine açılan bir davada, hekimin robotun uygun olmayan şekilde hatalı kullanımı nedeniyle; hastanenin ise cerrahının robotik cerrahi alanında uzmanlık eğitimi almasını sağlamamış olması nedeniyle hukuken sorumlu kılındığını belirtmiştir. ${ }^{20}$ Bu bağlamda hekimlerde dikkatin, tedbirin, temel becerinin, mesleki kitaplardaki bilgilerin güncel bilgilerle desteklenmesinin önemli olduğunu söyleyebiliriz.

Bayat'a göre, Hippokrates'in inandığı hekimliğin iyileştirici gücü ancak hastayla birlikte olduğunda, ona bütüncül yaklaştı̆̆ında, "önce hasta!" diyebildiğinde ortaya çıkacaktır. ${ }^{21}$ Araştırmamızda hekimlerin ileri teknoloji görüş ifadelerinde yüksek bir diğer ifadenin "Hasta çokluğu nedeniyle hekimin hastasına yeteri kadar zaman ayıramaması ve özeni gösterememesi klasik tıbbın muayene yöntemleri yerine yüksek teknolojinin kullanımını ön plana çıkarmaktadır." olduğu görülmektedir. Bu sonuç ile hızla gelişen teknoloji ve sürekli artan bilgi birikimi ile birlikte günümüzde "insancıl" tıp anlayışından uzaklaşıldığı, hekim hasta arasındaki teröpatik iletişiminin azalacağı düşünülmektedir. Bulut ve Civaner'in ilk çağdan günümüze kadar hekim-hasta-hastalık kavramlarını incelediği çalışmasında çalışmamızı destekler nitelikte günümüzde "Hasta yok, hastalık var." düşüncesinin hakim olduğunu görülmektedir. ${ }^{22}$ Bu noktada elleriyle temas etmemiş bir hekimin hastanın kendisine önem vermediği sonucu çıkarabileceği düşünülmektedir. Ayrıca hekimin klinik muayene yöntemleri kullanmadan teknoloji yöntemlerini kullanması hastada kendisinde ciddi bir hastalığın olabileceği düşüncesi ile anksiyete yaşamasına sebep olacağı da düşünülmektedir. Bununla birlikte tıp teknolojisi her ne kadar 
ilerlese de hastanın teşhis ve tedavisine karar vermede anamnez ve iyi klinik muayenenin yerinin korunacağı ifade edilebilir.

Çalışmamızda hekimlerin ileri teknoloji görüş ifadelerinde en düşük yüzdeye sahip ifadelerin "Yardımcı üreme teknikleri (YÜT) hayatın ve ölümün nerede başlayıp bittiği konusunda sorunlara neden olmaktadır." ve "Genetik gelişmeler bireylerin genetik özellikleri nedeniyle işlerini kaybetmesi ve damgalanmasına yol açmaktadır." olduğu belirlenmiştir. Bu sonuçlar üreme ve genetik teknolojisinin gelişmesinin yararlarının yanı sıra birçok etik sorunun yaşanmasına neden olması ve bu yaşanabilecek etik sorunların öngörülememesiyle açıklanabilir. Genetik test bilgisinin bireye açıklanması, yakınlarıyla paylaşılması ve saklanması ile ilgili etik sorunlar ortaya çıkabilir. Türk toplumunun yardımcı üreme tekniklerine bakış açısını araştıran bir çalışmada Türk toplumunun yardımcı üreme teknikleriyle doğan bir çocuğun ilerde bunu bilme hakkı olduğunu ve tedavinin aile ve doktor arasında bir sır olarak kalmasını istediği görülmektedir. ${ }^{23}$ Genetik bilginin yapısı özerklik, hayatın nerede başladığı ve bittiği, gizlilik, mahremiyet ve adalet gibi çağdaş tıp etiğinin önemli konularını içermektedir. ${ }^{23,24} \mathrm{Bu}$ kapsamda, genetik bilginin açıklanması ve mahremiyetine ilişkin olarak; genetik bilginin diğer tıbbi bilgilerden farklı olup olmadığı, genetik bilginin tamamen bireysel mahremiyet alanına giren bir bilgi olup olmadığı, hekimlerin ya da bireylerin genetik bilgiden etkilenebilecek kişileri uyarma yükümlülüğü olup olmadığı, bilginin nasıl paylaşılması ve nasıl korunması gerektiği konularında etik problemlerin yaşandığı alanda çalışmaların yapılması gerektiği düşünülmektedir.

Bu araştırmada hekimlerin ileri teknoloji görüş ifadelerinde en düşük yüzdeye sahip diğer bir ifadenin "ileri teknoloji gerektiren uygulamanın yapılmasına karar veren hekimle bu işlemi yapacak olan hekimin aynı olması kötüye kullanım riskini artırmaktadır." olduğu belirlenmiştir. Her ne kadar çalışmamızda bu sonuç düşük ortalamaya sahip olsa da, uygulamanın yapılmasına karar veren hekimle uygulamayı yapan hekimin aynı olması hekimin objektif davranmasını etkilemesi ve yapay gereksinimlerle gereksiz kullanımı artırması ile etik bir sorun oluşturabileceği düşünülmektedir.

\section{Sonuç ve Öneriler}

Hekimlerin ileri teknoloji kullanım görüşlerinin orta düzey olduğu belirlenmiştir. İlerleyen bilim ve teknoloji yaşamı kolaylaştırmakta, insan yaşamını uzatmakta, ancak bu ilişki aynı zamanda yeni etik problemler meydana getirmektedir. Hekim yetiştiren öğretim üyeleri, tıp eğitimi boyunca öğrencilerin mesleğe ilişkin tutumlarını şekillendirmektedirler. Bu bağlamda, teknolojiyi tedavide kullanmak ve değerlendirmek için uygun yöntemlerin belirlenmesinin önemli olduğu düşünülmektedir. Ayrıca ileri teknolojinin yaygınlaşması ile koruyucu hekimlik uygulamalarının ikinci plana itilmesinin önlenmesi, tıp eğitiminin teknoloji bağımlı hekimler yetiştirecek biçimde yapılanmasının önüne geçilmesi, klasik muayene ve yaklaşımların teknolojyle birlikte kullanılması büyük önem taşımaktadır.

\section{Bilgi}

Bu araştırmaya katılmaya gönüllü olan tüm hekimlere teşekkür ederiz. Yazarların beyan edecekleri bir çıkar çatışması yoktur.

\section{Etik Onay}

Sivas Cumhuriyet Üniversitesi Girişimsel Olmayan Klinik Araştırmalar Etik Kurulu'ndan (Karar No: 2019-09/16; Tarih: 11.09.2019) onay alınmıştır.

\section{Araştırmacı Katkı Oranı Beyanı}

Gülay Yıldırım: Fikir/Kavram, tasarım, denetleme, analiz ve yorum, kaynak taraması, makale yazımı, eleştirel inceleme, kaynaklar ve fon sağlama

Şerife Karagözoğlu: Fikir/Kavram, tasarım, denetleme, analiz ve yorum, makale yazımı, eleştirel inceleme 
Ezgi Yıldız: Fikir/Kavram, tasarım, veri toplama ve işleme, analiz ve yorum, kaynak taraması, makale yazımı, Sedat Özbay: Fikir/Kavram, tasarım, veri toplama ve işleme

\section{Kaynaklar}

1. Koçkaya G. Tatar M. (Ed.). Health Technology Assessment in Medical Devices (WHO Medical device technical series). World Health Organization Publications (Health Economics and Policy Association) 2013.

2. who.int [Internet]. World Health Organization: Association Of Health Technology Online Resources. [Avaible Date: 05.07.2020]. Avaible from: https://www.who.int/health-technology-assessment/about/healthtechnology/en/

3. Kırılmaz H, Kırılmaz Kılıç S. Benefits of Empirical Ethics Studies in Ethical Dilemmas in Health Care. Human and Human 2014;1(1):35-44

4. Efyy V, et al. Digital health: meeting the ethical and policy challenges. Swiss Med Wkly 2018; 148(3):1-9

5. Ataç A, Kurt E, Yurdakul SE. An Overview to Ethical Problems in Telemedicine Technology. Procedia - Social and Behavioral Sciences 2013;103(26):116-121

6. İzgi C. Personal health data in the context of the concept of privacy. Turkish Journal of Bioethics 2014;1(1):25-37.

7. Brall C, Schröder P, Maeckelberge E. Ethical aspects of digital health from a justice point of view. European Journal of Public Health 2019;29(3):18-22.

8. Avaner E. Fair Sharing of Advanced Technology Medical Devices and Limited Resources Example of Magnetic Resonance(MR) and Computerized Tomographic(CT) Devices. Turkish Journal of Bioethics 2019;6(3):100-108.

9. Sungur C. Unnecessary Use of Medical Imaging Services and Solution Suggestions Against It. Journal of Economic and Administrative Units of Kahramanmaraş Sütçü İmam University 2018.

10. Sargutan AE. Health Technology Management. Hacettepe Health Administration Magazine 2005;8(1):113-144.

11. Gülcemal E, Keklik B. An Investigation On Factors Affecting The Confidence of Patients to Physicians: A Research In Isparta. Mehmet Akif Ersoy University Journal of Social Sciences Institute 2018;8(14):64-87.

12. Cengiz I, Küçükay A. Medical Malpractics, Psychological Dimensions Of Medical Malpractice and Physician's Legal Responsibility. TAAD 2019;10(37):107-131.

13. Özer Ö, ve ark. Malpractise. Dicle Medical Journal 2015;42(3):394-397.

14. Tuncay I, Uçan V. Malpractice in orthopaedics and traumatology. Turkish Orthopedics and Traumatology Association Association Journal 2020;19:55-61.

15. Sezer B, Onan A, Elçin M. Information and Communication Techonogies in Continuing Medical Education. Turkiye Klinikleri J Med Educ-Special Topics 2016;1(3):1-6.

16. Satıcı Ö, Akkuş Z, Alp A. Investigation of attitudes regarding technology in teaching staff members of Medical Faculty by CHAID analysis. Dicle Med J 2009;36(4):267-274.

17. Zayim N, Yıldırım S, Saka O. Instructional Technology in Medical Education. Medical Informatics Turkey Proceedings 2005;39-45.

18. Parlak Börü Ş. Civil Liability Arsing From Robotic Surgeries. InULR 2019;10(2):758-775.

19. Clendenin BR, Conlon HA, Burns C. Overuse of diagnostic imaging for work-related injuries. Workplace health \& safety 2017:65(2):54-56.

20. Usluoğulları FH, Tıplamaz S, Yaycı N. Robotic surgery and malpractice. Turk J Urol 2017; 43(4): 425-428.

21. Bayat AH. Medical History. İstanbul: Traditional Medicine Association; 2010.

22. Bulut F, Civaner MM. Modern medicine is losing its humanistic essence: "Patients no more, but diseases" is the new motto now. Turkish Journal of Bioethics 2016;3(2):66-73.

23. Aktürk FC. Regard to In Vitro Fertiliziation Treatment in Turkish Society. (Masters Thesis) Afyon Kocatepe University Institute of Health Sciences 2006.

24. Akpınar A. Ethics in Using Genetic Information: Attitudes and Preferences of Physicians and Testees. (Doctoral Thesis). Kocaeli University Institute of Health Sciences 2010. 